\title{
Selective Potentiation of Insulin-mediated Glucose Disposal in Normal Dogs by the Sulfonylurea Glipizide
}

\author{
William S. Putnam, Dana K. Andersen, R. Scott Jones, and \\ Harold E. Lebovitz, Departments of Medicine, Physiology and Surgery, \\ Duke University Medical Center, Durham Veterans Administration Medical \\ Center, Durham, North Carolina 27710
}

\begin{abstract}
A B S T RAC T Investigative data have suggested that the extrapancreatic actions of the sulfonylureas may be paramount in their chronic antidiabetic action. The present study examines the effects of chronic sulfonylurea treatment on in vivo insulin action. Peripheral insulin levels, hepatic glucose production (Ra), and overall glucose disposal (Rd) were studied in six awake, normal dogs given both 0.5 and $1.0 \mathrm{mU} / \mathrm{kg}$ per min pork insulin for $2.5 \mathrm{~h}$. This produces stable hyperinsulinemia from 15 to $150 \mathrm{~min}$. Fasting euglycemia was held constant by the glucose clamp technique and averaged $99 \%$ basal glucose in all studies. Ra and Rd were determined from infusion of $\left[3-{ }^{3} \mathrm{H}\right]$ glucose, begun 90 min prior to insulin infusion. $10 \mathrm{mg}$ of the sulfonylurea glipizide, was given daily to the test animals for the 10 to $20 \mathrm{~d}$ following appropriate control studies, then was withheld for $24 \mathrm{~h}$, and the dogs were restudied. Glipizide treatment did not significantly alter basal glucose turnover, Ra, mean glucose values, or mean insulin levels as determined by radioimmunoassay. Increase in Rd above basal glucose turnover in response to insulin $(\Delta \mathrm{Rd})$ was significantly $(P<0.05)$ increased by glipizide treatment at both insulin dosage levels (paired analysis). At $1.0 \mathrm{mU} / \mathrm{kg}$ per min insulin, $\Delta \mathrm{Rd}$ rose from $2.6 \mathrm{mg} / \mathrm{kg}$ per min before glipizide to $6.5 \mathrm{mg} /$ $\mathrm{kg}$ per min after glipizide treatment. At $0.5 \mathrm{mU} / \mathrm{kg}$ per min insulin, $\Delta$ Rd went from $1.1 \mathrm{mg} / \mathrm{kg}$ per min before glipizide to $2.2 \mathrm{mg} / \mathrm{kg}$ per min after glipizide treatment. Glipizide treatment doubled the effects of insulin on $\mathrm{Rd}$, while showing no significant effect upon insulin suppression of Ra. We conclude that a significant extrapancreatic chronic action of glipizide lies in its ability to selectively potentiate $\mathrm{Rd}$.
\end{abstract}

Dr. Andersen's present address is State University of New York, Downstate Medical Center, Brooklyn, N. Y.

Received for publication 18 September 1980 and in revised form 28 November 1980.

\section{INTRODUCTION}

Insulin-independent diabetes mellitus is associated with insulin resistance $(1,2)$ and/or defective glucosemediated insulin secretion (3). While initial investigations suggested that sulfonylurea drugs might ameliorate the hyperglycemia of insulin-independent diabetes mellitus by increasing insulin secretion, more recent studies strongly support the hypothesis that extrapancreatic actions of sulfonylureas, particularly those related to the potentiation of insulin action, are primarily responsible for this therapeutic effect $(4,5)$.

In this regard, we have previously reported that chronic treatment of patients with insulin-independent diabetes with the sulfonylurea glipizide results in a significant increase in insulin-mediated glucose disposal from the plasma glucose pool (6). This effect of glipizide was reproduced in normal mice and was associated with a two- to threefold increase in hepatic plasma membrane insulin receptors (7). The data are compatible with the hypothesis that glipizide potentiates insulin action by increasing the number of insulin receptors on the plasma membrane of insulinsensitive tissues.

The present investigation was directed toward determining whether chronic glipizide therapy potentiates all of the actions of insulin on glucose metabolism equally or whether this sulfonylurea preferentially modifies only some of these actions. The data show that glipizide treatment in dogs potentiates the effects of insulin on overall glucose disposal but does not significantly alter the effects on hepatic glucose production.

\section{METHODS}

Dog model. The study was conducted on healthy mongrel dogs (body weight, $12-20 \mathrm{~kg}$ ). The dogs were maintained on a constant diet in the animal facility at Duke University Medical Center for at least $4 \mathrm{wk}$ prior to any metabolic investigations. 
The dogs were trained to stand quietly on study tables in the upright position, supported by canvas straps. All studies were done in conscious unanesthetized animals. After completion of control studies with insulin infusions of 0.5 and 1.0 $\mathrm{mU} / \mathrm{kg}$ per min, each animal was given the sulfonylurea glipizide (Pfizer Laboratories, New York), $5 \mathrm{mg}$ twice a day, orally. The 0.5 - and $1.0-\mathrm{mU} / \mathrm{kg}$ per $\mathrm{min}$ insulin infusion studies were repeated between the 10th and 20th $d$ of glipizide treatment. Glipizide therapy was withheld for $24 \mathrm{~h}$ preceding each study. Insulin infusion studies were done at least $1 \mathrm{wk}$ apart. The order of the insulin infusion dose was randomized. No correlation was noted between the duration of glipizide treatment and the responses observed.

Insulin infusion studies. Dogs were fasted for $18 \mathrm{~h}$ before each study. An 18-gauge intravenous polyethylene catheter was inserted into the saphenous vein of each hind limb. One catheter was used for withdrawal of peripheral blood samples; the other catheter was used for infusion of glucose, $\left[3-{ }^{3} \mathrm{H}\right]-$ glucose, and insulin.

A primed, continuous infusion of $\left[{ }^{3}{ }^{3} \mathrm{H}\right]$ glucose (New England Nuclear, Boston, Mass.) was begun 90 min before the experimental period. The ratio of the priming dose to the constant infusion was $\sim 90: 1$, with the continuous infusion at $646 \mathrm{nCi} / \mathrm{min}(0.155 \mathrm{ml} / \mathrm{min})$ throughout the control and experimental periods. Peripheral venous samples were withdrawn at $-40,-30,-20,-10$, and $0 \mathrm{~min}$ in heparinized (beef lung heparin, 1,000 U/ml., UpJohn Co., Kalamazoo, Mich.) syringes, immediately centrifuged, and aliquots of plasma saved for determination of glucose, specific activity of glucose and immunoreactive insulin (IRI). ${ }^{1}$

At $0 \mathrm{~min}$, a constant infusion of either 0.5 or $1.0 \mathrm{mU} / \mathrm{kg}$ per min of purified porcine insulin was begun in a peripheral vein and continued for $150 \mathrm{~min}$. A priming dose that was double the constant infusion dose was administered for the first $6 \mathrm{~min}$. The insulin solution was prepared in saline $(0.9 \%)$ with $1-1.5 \mathrm{ml}$ of each individual animal's plasma $/ 50 \mathrm{ml}$ of insulin infusate added to prevent insulin adsorption to glassware and the plastic infusion tubing. At $4 \mathrm{~min}$, glucose infusion was begun. The blood glucose was maintained at constant euglycemic basal levels by the glucose clamp technique (8). Appropriate corrections in the glucose infusion rate were made every $5 \mathrm{~min}$. Basal plasma glucose was maintained for $150 \mathrm{~min}$ by a servocontrolled negative feedback system coupled to a variable speed peristaltic infusion pump (Holter) delivering either a 5 or $10 \%$ glucose solution. The pump was calibrated prior to each study. The actual glucose concentration of the infusate was determined on a 1:100 dilution with a Beckman glucose analyzer (Beckman Instruments, Inc., Fullerton, Calif.) and since it was usually $92 \%$ of the presumed value, the actual value was used in the calculations.

In all experiments, samples for plasma glucose, plasma IRI, and plasma specific activity of glucose were obtained in heparinized syringes from the withdrawal catheter every 2 $\mathrm{min}$ for $10 \mathrm{~min}$ after time zero, then every $5 \mathrm{~min}$ for the duration of the study (150 min).

Chemical analyses. Plasma glucose concentrations were measured in duplicate by the glucose oxidase method using the Beckman glucose analyzer. This allowed determination of plasma glucose concentration within 2-3 min of withdrawal of the heparinized blood sample. Plasma IRI was assayed at 5-min intervals for each study using the double antibody radioimmunoassay technique with porcine insulin as the standard (9).

${ }^{1}$ Abbreviations used in this paper: IRI, immunoreactive insulin; Ra, the rate of endogenous glucose production; $\mathrm{Rd}$, the rate of overall glucose utilization.
To determine the specific activity of glucose, plasma samples from 5-min intervals of each study were deproteinized with perchloric acid and neutralized with potassium hydroxide (10). A 1.0-ml aliquot of the supernate was frozen and lyophilized to remove tritiated water. The dry residue was dissolved with $0.4 \mathrm{ml}$ of water and $5 \mathrm{ml}$ of Aquasol (New England Nuclear), and counts per minute determined with a liquid scintillation spectrometer. The specific activity of glucose (using the glucose concentrations obtained from the Beckman glucose oxidase method) was expressed as nanocuries per milligram.

Statistical calculations. In the basal state when a dynamic equilibrium prevailed ( $t=-40$ to $0 \mathrm{~min}$ ), the glucose turnover rate (milligrams per kilogram per minute) was calculated by the isotopic dilution equation: $R t=R a=R d=F / S A$, where $R t=$ the rate of glucose turnover, $R a=$ the rate of endogenous glucose production, $\mathbf{R d}=$ the rate of overall glucose utilization, $\mathbf{F}=$ the rate of infusion of the tracer (nanocuries per kilogram per minute $=646 \mathrm{nCi} / \mathrm{min}$ in all studies), and $\mathrm{SA}=$ the specific activity of plasma glucose at equilibrium (nanocuries per milligram). Since the liver is essentially the only source of glucose in the postabsorptive state, Ra can be assumed to be the rate of hepatic glucose production. In nonsteady states (during the experimental period), Ra and Rd were calculated by Steele's equations (11) in their algebraic form for continuously overlapping 20-min intervals (10-30, 15-35, $20-40$, etc.), assigning the value for the interval to the midpoint of that interval. In the equations, $200 \mathrm{ml} / \mathrm{kg}$ was used for $\mathrm{V}$ (glucose distribution volume) (12), and the pool fraction was assumed to be 0.65 according to Cowan and Hetenyi (13). The calculated Ra from Steele's equations minus the exogenous glucose infused ( 5 min average previous to the Ra and Rd interval midpoints) was assumed to be the endogenous glucose production (hepatic glucose production, Ra). The assay of glucose turnover by the primed-constant infusion and the pool-fraction technique has been validated for both steady and nonsteady states (14).

Two hour-long intervals were used for data comparisons (30-90 min and 90-150 min). The 13 mean values each for $\mathrm{Ra}, \mathrm{Rd}$, and plasma IRI for these periods were determined for each individual animal, then the time period means were averaged and expressed as mean \pm SEM. $\Delta R$ a and $\Delta R d$ were computed for each data point by taking the difference between that data point and basal glucose turnover. Means for time intervals for $\Delta R a$ and $\Delta R d$ were constructed in the same manner as for Ra and Rd. Statistical analysis was performed using Student's $t$ test for paired and unpaired comparisons (15).

\section{RESULTS}

Characteristics of the glucose clamp model. The experimental design used in these studies provides stable euglycemic glucose values and achieves steadystate peripheral plasma insulin levels. In each individual dog study the plasma glucose was maintained at 92 to $106 \%$ of the basal value, with an average of $99 \%$. Coefficients of variation of plasma glucose in individual animals ranged for 2.1 to $7.0 \%$ with an average of $4.3 \%$. The steady-state insulin level in individual animals from 15 to 150 min varied by $<5 \%$.

Effect of glipizide on insulin-mediated effects. Figs. 1 and 2 show the mean data obtained during the peripheral $1.0 \mathrm{mU} / \mathrm{kg}$ per min insulin infusions in dogs during the control studies and while on glipizide 


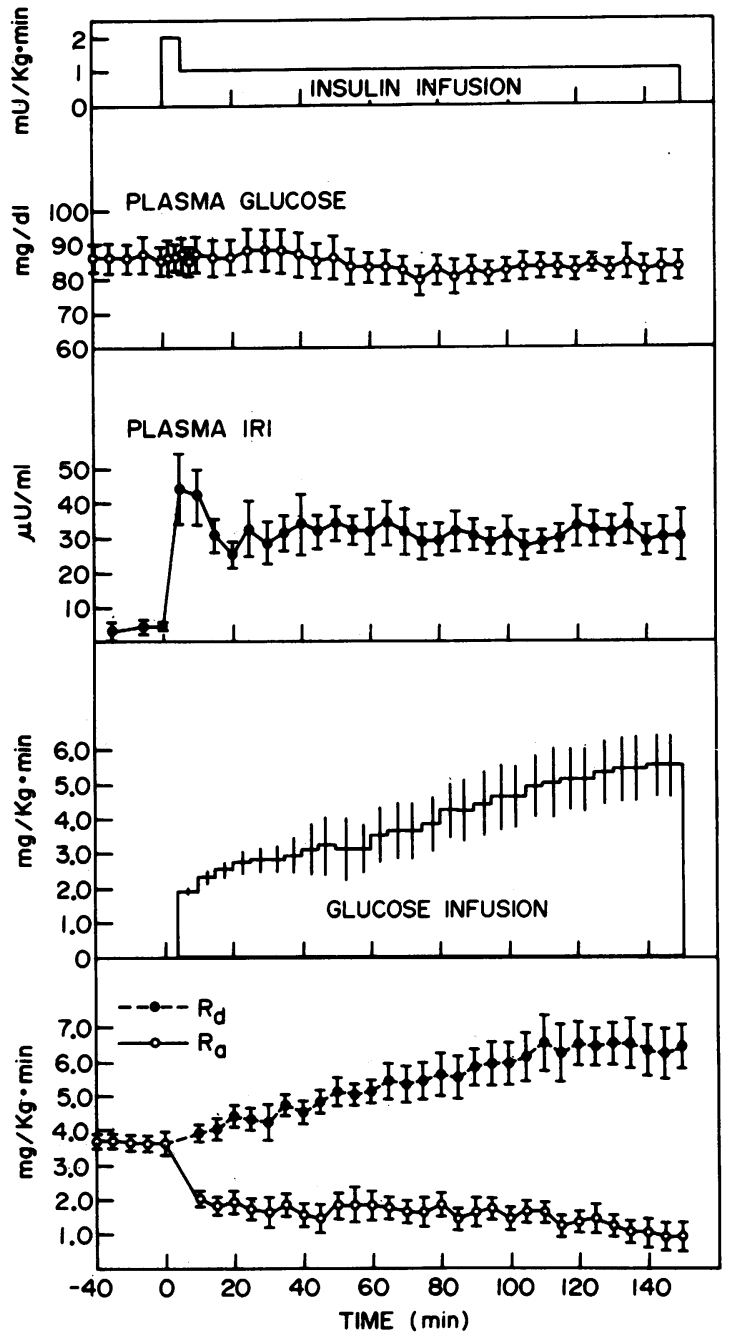

FIGURE 1 The effects of peripheral $1 \mathrm{mU} / \mathrm{kg}$ per min insulin infusion in six normal dogs. The first panel depicts the primed continuous insulin infusion. The second panel shows the euglycemia maintained during the glucose clamp (see Methods). The third panel illustrates the steady state square wave of hyperinsulinemia maintained throughout the study. The fourth panel illustrates the steadily increasing glucose infusions required to maintain euglycemia. The fifth panel shows hepatic glucose production ( $R a$ ) depicted by the open circles and overall glucose disposal (Rd) depicted by the closed circles during the course of the study (see Methods). $\mathrm{Ra}$ is decreased and $\mathrm{Rd}$ is increased by the insulin infusion. Each data point is the mean \pm SE.

treatment. Mean plasma glucose and insulin levels are quite constant in each study group and are comparable between control and glipizide treatment studies. Hepatic glucose production $(\mathrm{Ra})$ behaves the same during control and glipizide treatment, declining rapidly and then stabilizing between 1.0 and $1.5 \mathrm{mg} / \mathrm{kg}$ per min. Overall glucose disposal (Rd) is much greater during glipizide treatment. This is reflected in the

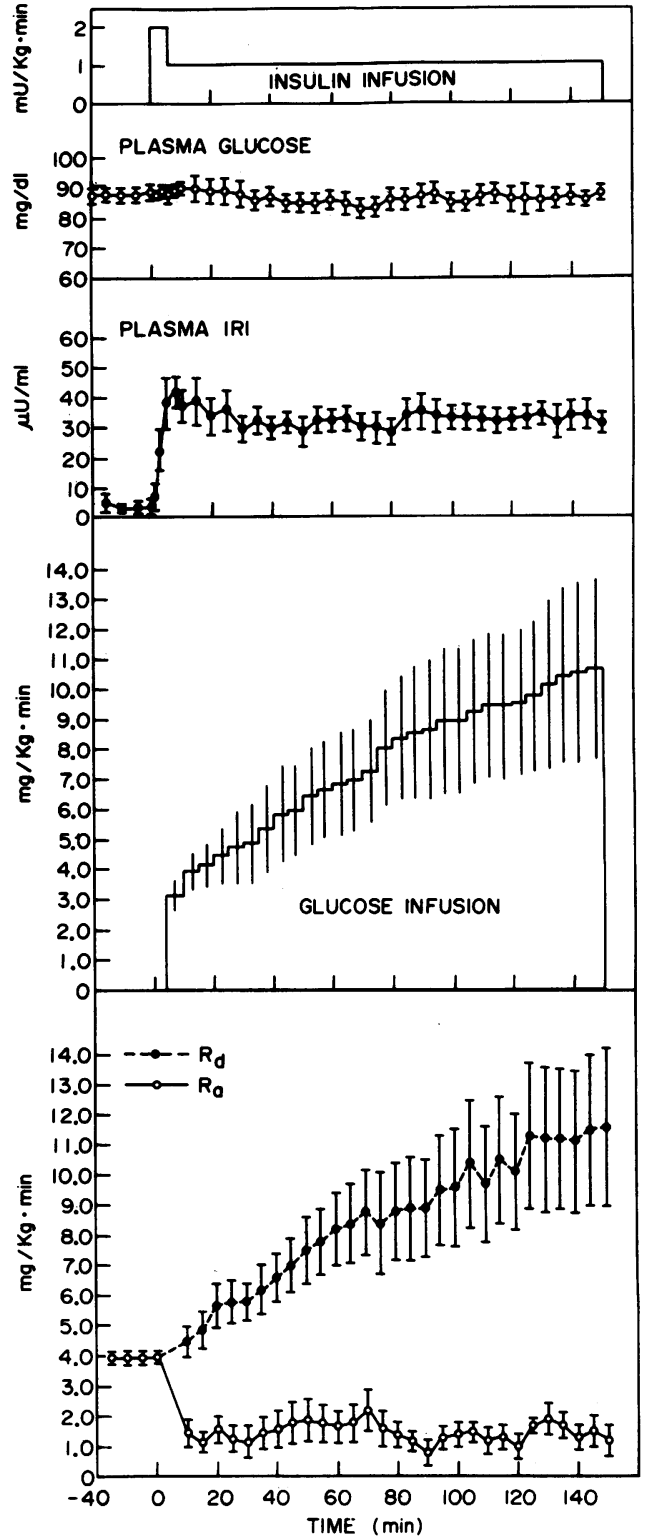

Figure 2 The effects of peripheral $1 \mathrm{mU} / \mathrm{kg}$ per min insulin in the same six dogs as in Fig. 1 during chronic glipizide treatment. The five panels are as described in the legend for Fig. 1. The steady state euglycemia and square wave plasma insulin levels are the same as in the control studies shown in Fig. 1. The glucose infusion rate necessary to maintain the steadystate euglycemia was approximately twice as much during glipizide treatment as in the control state. Insulin suppression of hepatic glucose production was unaltered by glipizide treatment but insulin-mediated overall glucose disposal was increased about twofold. Data are mean $\pm S E$.

marked difference in glucose infusion rates between the control and glipizide treatment studies.

The mean plasma glucose values (milligrams per deciliter) for control $(0.5 \mathrm{mU} / \mathrm{kg}$ per min dose $86 \pm 3.6$; 
$1 \mathrm{mU} / \mathrm{kg}$ per $\mathrm{min}$ dose $84 \pm 4.1$ ) and glipizide-treated $(0.5 \mathrm{mU} / \mathrm{kg}$ per min dose $84 \pm 4.1 ; 1 \mathrm{mU} / \mathrm{kg}$ per min dose $87 \pm 2.7$ ) studies are comparable at both insulin infusion rates. Mean plasma IRI levels (microunits per milliliter) for control $(0.5 \mathrm{mU} / \mathrm{kg}$ per min dose $17 \pm 2.9 ; 1 \mathrm{mU} /$ $\mathrm{kg}$ per min dose $30.9 \pm 4.5)$ and glipizide-treated $(0.5$ $\mathrm{mU} / \mathrm{kg}$ per min dose $18.3 \pm 1.6 ; 1.0 \mathrm{mU} / \mathrm{kg}$ per $\mathrm{min}$ $32.1 \pm 2.8)$ studies are also comparable at both insulin infusion rates. The constancy of the insulin infusions is shown by the constancy of mean plasma IRI during the 30 to 90 - and 90 to 150 -min intervals (data not shown).

Table I gives the individual dog's $\Delta \mathrm{Ra}$ and $\Delta \mathrm{Rd}$ values for the time periods 30-90- and 90-150 min for the peripheral $0.5 \mathrm{mU} / \mathrm{kg}$ per min insulin infusion studies, before and after glipizide treatment. As can be seen, while basal glucose turnover and $\Delta R$ a are unaffected by glipizide treatment, $\Delta \mathrm{Rd}$ is consistently higher after glipizide treatment.

Table II gives the same data for peripheral $1.0 \mathrm{mU} /$ $\mathrm{kg}$ insulin infusion studies. As with the lower insulin infusion dose, $\Delta \mathrm{Rd}$ is consistently higher after glipizide treatment while basal glucose turnover and $\Delta R a$ are unaffected.

Thus no significant change in $\Delta \mathbf{R a}$ with glipizide treatment at any insulin level or time period occurred. Individual changes in $\Delta \mathbf{R a}$ are both positive and nega- tive in approximately equal numbers. Net change in $\Delta \mathrm{Rd}$, however, though highly variable, is consistently positive. A significant increase $(P<0.05)$ in $\Delta R d$ attributable to glipizide treatment occurs at each insulin infusion rate and time period studied.

Relationship of initial insulin sensitivity to glipizide potentiation of insulin-mediated overall glucose disposal. Fig. 3 illustrates positive correlation between $\Delta \mathrm{Rd}$ during the control studies (a measure of insulin sensitivity) and the net increase in $\Delta R d$ due to glipizide treatment (a measure of response to glipizide). Thus, the greater the sensitivity that an individual animal has to insulin's effect on overall glucose disposal, the more responsive it appears to be to glipizide potentiation of this effect.

\section{DISCUSSION}

The data presented in this study in normal dogs show that chronic treatment with the sulfonylurea glipizide increases the effectiveness of physiological concentrations of insulin in overall glucose uptake; but, surprisingly, it has no significant effect on insulin suppression of hepatic glucose production. Since suppression of hepatic glucose production is more sensitive to physiologic concentrations of insulin than is net overall uptake of glucose (16-19), these findings indicate that

TABLE I

Effect of Glipizide Treatment on the Changes in Hepatic Glucose Production ( $\Delta R$ R) and Overall Glucose Disposal ( $\Delta R d)$ in Response to Infusion of $0.5 \mathrm{mU} / \mathrm{kg}$ per min of Insulin

\begin{tabular}{|c|c|c|c|c|c|c|}
\hline \multicolumn{2}{|c|}{ Animal } & \multirow{2}{*}{$\begin{array}{c}\begin{array}{c}\text { Basal glucose } \\
\text { turnover }\end{array} \\
\text { mg/kg per min }\end{array}$} & \multicolumn{2}{|c|}{$\Delta \mathrm{Ra}(\mathrm{mg} / \mathbf{k g}$ per $\mathrm{min})$} & \multicolumn{2}{|c|}{$\Delta \mathbf{R d}(\mathbf{m g} / \mathbf{k g}$ per $\mathrm{min})$} \\
\hline & & & $30-90 \min$ & $90-150 \mathrm{~min}$ & $30-90 \min$ & $90-150 \min$ \\
\hline 1 & $\begin{array}{l}\text { C } \\
\text { Glip }\end{array}$ & $\begin{array}{l}4.4 \pm 0.2 \\
3.5 \pm 0.1\end{array}$ & $\begin{array}{l}-1.7 \pm 0.1 \\
-1.9 \pm 0.1\end{array}$ & $\begin{array}{l}-1.7 \pm 0.1 \\
-2.0 \pm 0.2\end{array}$ & $\begin{array}{l}0.1 \pm 0.1 \\
0.9 \pm 0.1\end{array}$ & $\begin{array}{l}0.7 \pm 0.1 \\
1.9 \pm 0.2\end{array}$ \\
\hline 2 & $\begin{array}{l}\text { C } \\
\text { Glip }\end{array}$ & $\begin{array}{l}2.9 \pm 0.1 \\
2.9 \pm 0.0\end{array}$ & $\begin{array}{l}-1.1 \pm 0.2 \\
-2.2 \pm 0.2\end{array}$ & $\begin{array}{l}-2.0 \pm 0.2 \\
-2.5 \pm 0.2\end{array}$ & $\begin{array}{l}1.3 \pm 0.2 \\
2.0 \pm 0.2\end{array}$ & $\begin{array}{l}1.4 \pm 0.1 \\
3.8 \pm 0.1\end{array}$ \\
\hline 3 & $\begin{array}{l}\text { C } \\
\text { Glip }\end{array}$ & $\begin{array}{l}3.3 \pm 0.1 \\
3.1 \pm 0.1\end{array}$ & $\begin{array}{l}-2.2 \pm 0.1 \\
-1.9 \pm 0.2\end{array}$ & $\begin{array}{l}-3.3 \pm 0.1 \\
-2.1 \pm 0.1\end{array}$ & $\begin{array}{l}1.1 \pm 0.1 \\
1.3 \pm 0.1\end{array}$ & $\begin{array}{l}1.8 \pm 0.1 \\
1.9 \pm 0.1\end{array}$ \\
\hline 4 & $\begin{array}{l}\text { C } \\
\text { Glip }\end{array}$ & $\begin{array}{l}3.5 \pm 0.1 \\
3.6 \pm 0.1\end{array}$ & $\begin{array}{l}-1.5 \pm 0.1 \\
-0.5 \pm 0.1\end{array}$ & $\begin{array}{l}-1.8 \pm 0.1 \\
-0.5 \pm 0.1\end{array}$ & $\begin{array}{l}0.0 \pm 0.1 \\
0.6 \pm 0.1\end{array}$ & $\begin{array}{l}0.1 \pm 0.1 \\
0.9 \pm 0.1\end{array}$ \\
\hline 5 & $\begin{array}{l}\text { C } \\
\text { Glip }\end{array}$ & $\begin{array}{l}3.3 \pm 0.0 \\
3.1 \pm 0.0\end{array}$ & $\begin{array}{l}-0.7 \pm 0.1 \\
-0.3 \pm 0.1\end{array}$ & $\begin{array}{l}-0.6 \pm 0.1 \\
-0.5 \pm 0.2\end{array}$ & $\begin{array}{r}-0.2 \pm 0.0 \\
0.0 \pm 0.1\end{array}$ & $\begin{array}{r}-0.1 \pm 0.2 \\
0.4 \pm 0.1\end{array}$ \\
\hline 6 & $\begin{array}{l}\text { C } \\
\text { Glip }\end{array}$ & $\begin{array}{l}3.5 \pm 0.1 \\
3.2 \pm 0.1\end{array}$ & $\begin{array}{l}-2.1 \pm 0.1 \\
-1.2 \pm 0.1\end{array}$ & $\begin{array}{l}-2.0 \pm 0.1 \\
-1.9 \pm 0.1\end{array}$ & $\begin{array}{l}1.2 \pm 0.1 \\
2.5 \pm 0.2\end{array}$ & $\begin{array}{l}2.4 \pm 0.3 \\
4.5 \pm 0.2\end{array}$ \\
\hline \multicolumn{3}{|c|}{$\begin{array}{c}\text { Mean } \pm S E \text { of differences } \\
\text { between } C \text { and Glip }\end{array}$} & $0.2 \pm 0.3$ & $0.3 \pm 0.3$ & $0.6 \pm 0.2^{*}$ & $1.2 \pm 0.4 \ddagger$ \\
\hline
\end{tabular}

Basal glucose turnover is mean $\pm \mathrm{SE}$ of five values $(-40,-30,-20,-10,0 \mathrm{~min}) . \Delta \mathrm{Ra}$ and $\Delta \mathrm{Rd}$ are mean $\pm S E$ of 13 values (30 to $90 \mathrm{~min}$ ) and 12 values (90-150 min). C, control; Glip, glipizide treatment. $* P<0.02$.

$\ddagger P<0.05$. 
TABLE II

Effect of Glipizide Treatment on the Change in Hepatic Glucose Production ( $\Delta$ Ra) and Overall Glucose Disposal $(\Delta R d)$ in Response to Infusion of $1.0 \mathrm{mU} / \mathrm{kg}$ per min of Insulin

\begin{tabular}{|c|c|c|c|c|c|c|}
\hline \multicolumn{2}{|c|}{ Animal } & \multirow{2}{*}{$\begin{array}{c}\begin{array}{c}\text { Basal glucose } \\
\text { turnover }\end{array} \\
\text { mg/kg per min }\end{array}$} & \multicolumn{2}{|c|}{$\Delta \mathrm{Ra}(\mathrm{mg} / \mathrm{kg}$ per $\min )$} & \multicolumn{2}{|c|}{$\Delta \mathrm{Rd}(\mathrm{mg} / \mathrm{kg}$ per $\mathrm{min})$} \\
\hline & & & $30-90 \min$ & $90-150 \mathrm{~min}$ & $30-90 \min$ & $90-150 \mathrm{~min}$ \\
\hline \multirow[t]{2}{*}{1} & $\mathrm{C}$ & $4.0 \pm 0.1$ & $-1.9 \pm 0.1$ & $-2.7 \pm 0.1$ & $1.2 \pm 0.1$ & $2.1 \pm 0.1$ \\
\hline & Glip & $4.6 \pm 0.1$ & $-4.6 \pm 0.1$ & $-4.6 \pm 0.1$ & $5.5 \pm 0.5$ & $10.1 \pm 0.5$ \\
\hline \multirow[t]{2}{*}{2} & $\mathrm{C}$ & $3.3 \pm 0.1$ & $-1.9 \pm 0.3$ & $-2.4 \pm 0.2$ & $1.9 \pm 0.4$ & $2.5 \pm 0.2$ \\
\hline & Glip & $3.7 \pm 0.1$ & $-3.6 \pm 0.2$ & $-3.7 \pm 0.3$ & $3.0 \pm 0.4$ & $6.6 \pm 0.3$ \\
\hline \multirow[t]{2}{*}{3} & C & $3.1 \pm 0.1$ & $-2.1 \pm 0.1$ & $-2.0 \pm 0.1$ & $1.6 \pm 0.2$ & $3.3 \pm 0.1$ \\
\hline & Glip & $3.6 \pm 0.1$ & $-1.6 \pm 0.1$ & $-1.7 \pm 0.1$ & $2.2 \pm 0.1$ & $3.2 \pm 0.1$ \\
\hline \multirow[t]{2}{*}{4} & $\mathrm{C}$ & $4.1 \pm 0.0$ & $-1.8 \pm 0.2$ & $-2.9 \pm 0.2$ & $0.6 \pm 0.1$ & $1.4 \pm 0.1$ \\
\hline & Glip & $3.4 \pm 0.1$ & $-1.3 \pm 0.1$ & $-1.5 \pm 0.0$ & $1.5 \pm 0.1$ & $2.1 \pm 0.1$ \\
\hline \multirow[t]{2}{*}{5} & C & $3.6 \pm 0.0$ & $-1.1 \pm 0.1$ & $-0.9 \pm 0.1$ & $0.5 \pm 0.0$ & $0.8 \pm 0.1$ \\
\hline & Glip & $4.3 \pm 0.0$ & $-1.3 \pm 0.4$ & $-2.1 \pm 0.1$ & $1.9 \pm 0.4$ & $2.4 \pm 0.1$ \\
\hline \multirow[t]{2}{*}{6} & $\mathrm{C}$ & $3.5 \pm 0.1$ & $-3.0 \pm 0.2$ & $-3.1 \pm 0.1$ & $3.3 \pm 0.3$ & $5.6 \pm 0.1$ \\
\hline & Glip & $3.6 \pm 0.0$ & $-2.2 \pm 0.3$ & $-2.3 \pm 0.3$ & $8.7 \pm 0.7$ & $14.8 \pm 0.6$ \\
\hline \multicolumn{7}{|c|}{ Mean $\pm \mathrm{SE}$ of difference } \\
\hline \multicolumn{3}{|c|}{ between C and Glip } & $-0.5 \pm 0.6$ & $-0.3 \pm 0.5$ & $2.3 \pm 0.8^{*}$ & $3.9 \pm 1.5^{*}$ \\
\hline
\end{tabular}

Basal glucose turnover is mean $\pm \mathrm{SE}$ of five values $(-40,-30,-20,-10,0 \mathrm{~min}) . \Delta \mathrm{Ra}$ and $\Delta \mathrm{Rd}$ are mean $\pm \mathrm{SE}$ of 13 values (30 to $90 \mathrm{~min}$ ) and 12 values (90-150 min). C, control; Glip, glipizide treatment.

$* P<0.05$.

there is some selectivity or differential sensitivity of insulin responsive sites to this extra-pancreatic effect of glipizide. Thus, sulfonylurea treatment may not merely mimic insulin's action on glucose metabolism, but may qualitatively alter it. The sensitivity of each individual dog to glipizide potentiation of insulinmediated overall glucose disposal correlated well with its base-line sensitivity to this action of insulin suggesting that glipizide facilitated an existing mechanism.

The experimental design does not absolutely exclude glipizide having some, but albeit a much lesser effect, on insulin-mediated suppression of hepatic glucose production as compared with insulin-mediated overall glucose disposal. The effects of higher concentrations of insulin or more prolonged glipizide therapy were not studied.

Insulin resistance has been shown to be a significant factor in the metabolic aberrations of patients with insulin-independent (type II) diabetes mellitus (1-3). Chronic sulfonylurea treatment of these patients is associated with a significant potentiation of insulin action and a partial or complete amelioration of this insulin resistance $(5,6,20)$. It is unclear as to whether the insulin resistance is uniform at all insulinsensitive sites or is selective. Kimmerling et al. (21) have presented data which show that insulin action in increasing glucose uptake is markedly impaired in patients with chemical diabetes, while insulin action in suppressing hepatic glucose production is only slightly decreased. In patients with fasting hyperglycemia, both aspects of insulin action appear to be equally impaired (21). Our data indicate that if chronic glipizide treatment has the same effects in diabetic man as in our normal dogs, it should selectively ameliorate the early defect in insulin-mediated glucose uptake found in patients with chemical diabetes. If this were so, it could explain why sulfonylurea therapy is so beneficial in patients with the recent onset of a modestly severe insulin resistant (normal to elevated plasma insulin levels) diabetes mellitus.

The specific mechanism of insulin resistance in patients with insulin-independent diabetes mellitus is unclear. Olefsky and Reaven (22) have demonstrated decreased insulin receptors on circulating monocytes in patients with insulin-independent diabetes mellitus (22). Insulin resistance was shown to correlate well with the decrease in insulin receptors in individuals with chemical diabetes but not in those with overt diabetes and fasting hyperglycemia (23). Other investigators have suggested that the mechanism of insulin resistance is due to a postreceptor defect that results in hyperglycemia and increased insulin secretion $(24$, 25). The elevated plasma insulin levels would lead to a 


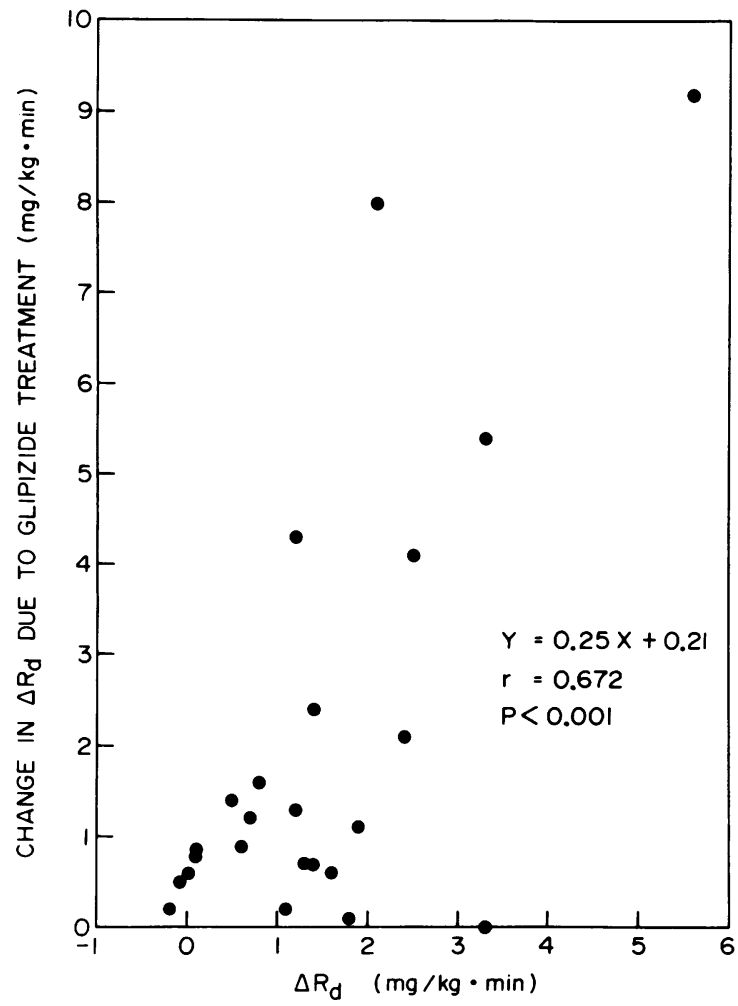

Figure 3 Correlation between the effect of glipizide treatment in increasing insulin-mediated overall glucose disposal and the control insulin-mediated overall glucose disposal in normal dogs. The data show that the glipizide effect is greatest in those animals who are most sensitive to insulin in the control state.

decrease in plasma membrane insulin receptors through the mechanism of "down regulation." If the primary mechanism for insulin resistance is a decrease in insulin receptors, then any factor that increases the number of receptors should ameliorate the resistance. If the primary defect is a postreceptor event, then alterations in plasma membrane receptors by various therapeutic agents would be secondary events and of little consequence.

Treatment of patients with insulin-independent diabetes mellitus with sulfonylurea drugs increases circulating monocyte insulin receptors (26). However, similar increases in circulating monocyte insulin receptors have been reported by effective treatment of the same type of diabetic patients with diet (27), so that it is unclear whether the increase in insulin receptors is the result of the effective treatment of the diabetic state or the consequence of oral sulfonylurea therapy. Chronic sulfonylurea treatment of normal mice that did not alter fasting plasma glucoses or insulins did cause increased insulin sensitivity and was associated with a two- to threefold increase in the number of hepatic plasma membrane insulin receptors (7).
Several recent reports show that sulfonylureas influence the internalization of plasma membrane receptors in vitro $(28,29)$, and Prince and Olefsky (30) have reported that sulfonylureas cause a slight increase in the number of insulin receptors on human fibroblasts grown in vitro and significantly suppress down regulation of the insulin receptor by insulin in the same model system (30). Thus there is evidence to support either the hypothesis that sulfonylureas directly increase insulin receptors and this accounts for their extrapancreatic effects in potentiating insulin action, or that sulfonylureas alter postreceptor insulin action and the change in insulin receptors is a secondary phenomenon.

The findings in the present study are at variance with a number of early observations on the effects of sulfonylureas on the liver. Several initial reports proposed that sulfonylureas decreased hepatic glucose output and that this effect could not be mimicked by insulin (31-33). Those data were subsequently refuted by a number of studies that showed that sulfonylurea administration caused a decrease in hepatic glucose output and had little or no discernable effect on peripheral glucose uptake and that insulin caused very similar effects (34-36). All of those early studies used acute administration of the sulfonylurea and did not control the glucose level. Most likely the observed effects were related to the increased secretion of insulin. Colwell (37) reported that acutely administered tolbutamide but not acetohexamide potentiated insulin action when both were infused into the portal vein of dogs (37). He measured the fall in peripheral blood glucose but did not specifically assess hepatic effects. Blumenthal (38), using an in vitro liver perfusion, showed that chlorpropamide augments insulin action in inhibiting glucagon-stimulated glucose production (38). The relevance of this in vitro model to the in vivo studies is unclear.

Several experimental features that are included in our studies strengthen the validity of our results. The blood glucose was kept normal throughout the studies. Conscious normal dogs were used. Each animal served as its own control. The sulfonylurea was given for 10-20 d allowing for chronic effects to occur. Hepatic glucose production and overall glucose disposal were determined. Physiological concentrations of insulin were used. The use of normal animals in this initial phase of the study obviated any possible effects due to the regulation of hyperglycemia as would occur in diabetic animals.

The effect of chronic glipizide administration in increasing insulin-mediated overall glucose disposal could be the result of an increase in peripheral glucose uptake, an increase in hepatic glucose uptake or a combination of both. We did not measure glucose differences across the liver and do not know if changes in hepatic glucose uptake occurred. Ample data in the 
literature indicate that chronic sulfonylurea treatment potentiates insulin-mediated glucose uptake in skeletal muscle $(4,39)$. Acute administration of sulfonylureas does not increase insulin-mediated peripheral glucose uptake $(40,41)$.

The present study, which indicates that chronic glipizide treatment of normal dogs potentiates insulinmediated overall glucose disposal and has no significant effect on insulin-mediated hepatic glucose production, suggests that chronic sulfonylurea therapy qualitatively alters insulin action. If such effects occur in diabetic patients they could explain some of the enigmas in our understanding of the usefulness of sulfonylurea therapy. Elucidation of the mechanism of this selective effect could provide unique insights into understanding insulin action and perhaps the nature of the resistance to insulin action in patients with insulin-independent diabetes mellitus.

\section{ACKNOWLEDGMENTS}

We acknowledge the technical assistance of Clarice Wellman, Kenneth Christian, and Ezra Hayes.

This study was supported by grants from Pfizer Laboratories, the North Carolina United Way Fund, the Veterans Administration (4790), and the National Institutes of Arthritis, Metabolic and Digestive Diseases (AM 01324 and AM 16421).

\section{REFERENCES}

1. Reaven, G. M., R. Bernstein, B. Davis, and J. M. Olefsky. 1976. Nonketotic diabetes mellitus: insulin deficiency or resistance? Am. J. Med. 60: 80-88.

2. Reaven, G. M. 1980. Insulin independent diabetes mellitus: metabolic characteristics. Metab. Clin. Exp. 29: 445-454.

3. Lebovitz, H. E., and M. N. Feinglos. 1980. Therapy of insulin independent diabetes mellitus: general considerations. Metab. Clin. Exp. 29: 474-481.

4. Feldman, J. M., and H. E. Lebovitz. 1969. Appraisal of the extrapancreatic actions of sulfonylureas. Arch. Intern. Med. 123: 314-322

5. Lebovitz, H. E., and M. N. Feinglos. 1978. Sulfonylurea drugs: mechanism of antidiabetic action and therapeutic usefulness. Diabetes Care. 1: 189-198.

6. Lebovitz, H. E., M. N. Feinglos, H. K. Bucholtz, and F. L. Lebovitz. 1977. Potentiation of insulin action: a probable mechanism for the anti-diabetic action of sulfonylurea drugs. J. Clin. Endocrinol. Metab. 45: 601-604.

7. Feinglos, M. N., and H. E. Lebovitz. 1978. Sulfonylureas increase the number of insulin receptors. Nature (Lond.). 276: $184-185$.

8. DeFronzo, R. A., J. D. Tobin, and R. Andres. 1979. Glucose clamp technique: a method for quantifying insulin secretion and resistance. Am. J. Physiol. 237(3): E214-223.

9. Morgan, C. R., and A. Lazarow. 1963. Immunoassay of insulin: two antibody system. Plasma insulin levels in normal, subdiabetic and diabetic rats. Diabetes. 12: $115-126$.

10. Bergmeyer, H.-U. 1965. Methods of Enzymatic Analysis. Academic Press, Inc., New York. 272.

11. Steele, R. 1959. Influence of glucose loading and of injected insulin on hepatic glucose output. Ann. N. Y. Acad. Sci. 82: 420-430.

12. McGuire, E. A. H., J. H. Helderman, J. D. Tobin, R. Andres, and M. Berman. 1976. Effects of arterial versus venous sampling on analysis of glucose kinetics in man. J. Appl. Physiol. 41: 565-573.

13. Cowan, J. S., and G. Hetenyi, Jr. 1971. Glucoregulatory responses in normal and diabetic dogs recorded by a new tracer method. Metab. Clin. Exp. 20: 360-372.

14. Radziuk, J., K. H. Norwich, and M. Vranic. 1974. Measurement and validation of nonsteady turnover rates with applications to the insulin and glucose systems. Fed. Proc. 33: $1855-1864$.

15. Snedecor, G. W., and W. G. Cochran. 1967. Statistical Methods. Iowa University Press, Ames, Iowa. 59-65.

16. Sacca, L., R. S. Sherwin, R. Hendler, and P. Felig. 1979. Influence of continuous physiologic hyperinsulinemia on glucose kinetics and counter-regulatory hormones in normal and diabetic humans. J. Clin. Invest. 63: 849-857.

17. Sacca, L., P. E. Cryer, and R. S. Sherwin. 1979. Blood glucose regulates the effects of insulin and counterregulatory hormones on glucose production in vivo. Diabetes. 28: 533-536.

18. Felig, P., and J. Wahren. 1971. Influence of endogenous insulin secretion on splanchnic glucose and amino acid metabolism in man. J. Clin. Invest. 50: 1702-1710.

19. Madison, L. L., B. Combes, R. Adams, and W. Strickland. 1960. The physiologic significance of the secretion of endogenous insulin into the portal circulation. III. Evidence for a direct immediate effect of insulin on the balance of glucose across the liver. J. Clin. Invest. 39: 507-522.

20. Beck-Nielson, H., O. Pederson, and H. O. Linskov. 1979. Increased insulin sensitivity and cellular insulin binding in obese diabetics following treatment with glibenclamide. Acta Endocrinol. 90: 451-462.

21. Kimmerling, G., W. C. Javorski, J. M. Olefsky, and G. M. Reaven. 1976. Locating the site(s) of insulin resistance in patients with nonketotic diabetes mellitus. Diabetes. 25: 673-678.

22. Olefsky, J. M., and G. M. Reaven. 1974. Decreased insulin binding to lymphocytes from diabetic patients. J. Clin. Invest. 54: 1323-1328.

23. Olefsky, J. M., and G. M. Reaven. 1977. Insulin binding in diabetes: relationships with plasma insulin levels and insulin sensitivity. Diabetes. 26: 680-688.

24. Kahn, C. R. 1980. The role of insulin receptors in insulin resistant states. Metab. Clin. Exp. 29: 455-466.

25. Crettaz, M., and B. Jeanrenaud. 1980. Postreceptor alterations in the states of insulin resistance. Metab. Clin. Exp. 29: 467-473.

26. Olefsky, J. M., and G. M. Reaven. 1976. Effects of sulfonylurea therapy on insulin binding to mononuclear leukocytes of diabetic patients. Am. J. Med. 60: 89-95.

27. Beck-Nielsen, H., O. Pederson, and N. S. Sorensen. 1980. Effects of dietary changes on cellular insulin binding and in vivo insulin sensitivity. Metab. Clin. Exp. 29: 482-487.

28. Davies, P. J. A., D. R. Davies, A. Levitski, F. R. Maxfield, P. Milhand, M. C. Willingham, and I. H. Pastan. 1980. Transglutaminase is essential in receptor mediated endocytosis of $\alpha 2$-macroglobulin and polypeptide hormones. Nature (Lond.). 283: 162-167.

29. Schlessinger, J., Y. Shechter, M. C. Willingham, and I. H. Pastan. 1978. Direct visualization of binding, aggregation and internalization of insulin and epidermal growth factor on living fibroblastic cells. Proc. Natl. Acad. Sci. U. S. A. 75(6): 2659-2663. 
30. Prince, M. J., and J. M. Olefsky. 1980. Direct in vitro effect of a sulfonylurea to increase human fibroblast insulin receptors. J. Clin. Invest. 66: 608-611.

31. Recant, L., and C. L. Fischer. 1957. Studies of the mechanism of tolbutamide hypoglycemia in animals and human subjects. Ann. N. Y. Acad. Sci. 71: 62-70.

32. Tarding, F., and P. Schambye. 1958. The action of sulphonylureas and insulin on the glucose output from the liver of normal dogs. Endokrinologie. 36: 222-228.

33. Schambye, P., and F. Tarding. 1959. Changes induced by insulin and tolbutamide in glucose output of the liver. Ann. N. Y. Acad. Sci. 74: 557-560.

34. Madison, L. L., B. Combes, R. H. Unger, and N. Kaplan. 1959. The relationship between the mechanism of action of the sulfonylureas and the secretion of insulin into the portal circulation. Ann. N. Y. Acad. Sci. 74: 548-556.

35. Craig, J. W., W. R. Drucker, M. Miller, H. Woodward, Jr., and V. Molzahn. 1959. A comparison of the influence of tolbutamide and small doses of insulin on the splanchnic output and peripheral uptake of glucose in man. Ann. N. Y. Acad. Sci. 74: 537-547.
36. Reichard, G. A., Jr., A. G. Jacobs, B. Friedman, P. R. Kimbel, N. J. Hochella, and S. Weinhouse. 1958. Effect of insulin and tolbutamide on production and utilization of blood sugar. Metab. Clin. Exp. 8: 486-493.

37. Colwell, A. R., Jr. 1964. Potentiation of insulin action on the liver by tolbutamide. Metab. Clin. Exp. 13: 1310-1317.

38. Blumenthal, S. A. 1977. Potentiation of the hepatic action of insulin by chloropropamide. Diabetes. 26: 485-489.

39. Feldman, J. M., and H. E. Lebovitz. 1969. An insulin dependent effect of chronic tolbutamide administration on the skeletal muscle carbohydrate transport system. Diabetes. 18: 84-95.

40. Butterfield, W. J. H., M. J. Whichelow, M. E. Abrams, J. S. Wakelin, and K. Mashiter. 1967. Studies of the effect of tolbutamide on the metabolism of the forearm tissues. In Tolbutamide . . . After Ten Years. W. J. H. Butterfield, and W. Van Westering, editors. Excerpta Med. Int. Congr. Ser. 149: 196-201.

41. Zinman, B., and R. I. Ogilvie. 1972. The acute effects of tolbutamide on forearm metabolism. J. Clin. Endocrinol. Metab. 35: 299-306. 